\title{
The Perception and Barriers of Peoples to Prevent Noncommunicable Diseases" Through Physical Activities: In the Case of Debre Markos and Fnoteselam Towns, Ethiopia
}

\author{
Birhanu Anjte* Awoke Tibebu \\ Department of Sport Science, College of Natural and Computational Sciences, \\ Debre Markos University PO box 269 Debre Markos, Ethiopia
}

\begin{abstract}
This study attempted to assess the habits and awareness of people towards physical exercise and its challenges and opportunities in the process of preventing selected NCD. To conduct this study the researchers delimited to Debre Markos and Fnoteselam towns in different respective population groups and offices. The total sample sizes were 2200 and a minimum of 600 sample respondents were taken by $10 \%$ rule among this 470 for questionnaire and 130 for interview respondents. Each office has been selected by stratified sampling based on purposively expected availability of information and participants were categorized according to their demographic placement such as sex, age, education and habit of involvement then followed by simple random sampling techniques. In this research, the data collection tools employed questionnaires, interview with focus group discussion and document were analyzed in triangulation manner. The reason why the researchers chooses these methods is to get valuable and reliable data for outshined barriers of physical exercise, causes of prevention of disease (NCD) in the case of Debre Markos and Fenoteselam towns. After that the questionnaires were administered and the data was collected, tailed, analyzed and logical conclusion and recommendation was reported.
\end{abstract}

Keywords: Barriers, Perception, Physical exercise, Physical fitness

DOI: $10.7176 / \mathrm{JHMN} / 72-03$

Publication date:March $31^{\text {st }} 2020$

\section{INTRODUCTION}

Globally, NCDs are responsible for death and disability on a massive scale. NCDs are the single biggest cause of death in the world of 56 million deaths in the world in 2012, 38 million (68\%) were due to all NCDs.[1] The burden of NCD mortality has risen rapidly in recent decades. The proportion of deaths attributed to all NCDs rose from $57 \%$ in 1990 to $65 \%$ in 2008.[2,3] The human suffering caused by this burden of disease also translates to economic loss. Globally, it has been estimated that the cumulative cost of lost output due to the four major NCDs combined will lead to a loss of US\$30 trillion dollars between 2011 and 2030.[4] When mental health conditions are added the figure rises to US\$47 trillion when divided by the 20-year period this loss is equivalent to about $5 \%$ of global GDP at 2010 levels. [4] The NCD epidemic has more impact on low-income groups, since these are more exposed to risk factors and have poorer access to health services. These diseases create a vicious circle which worsens poverty for these families (WHO, 2011).[5] Furthermore, health system expenses with NCD represent an increasing impact. In Ethiopia, NCD are one of the main causes for hospitalization.

Physical activity is a key component of healthy lifestyle and disease prevention.[6] Physical activity has a major impact on health. Some effects are well established; as a major component of energy expenditure, physical activity has a great influence on energy balance and body composition. It is also recognized that physical activity is a major independent modifiable risk factor which has a protective effect on cardiovascular disease (CVD), stroke, type 2 diabetes, colon and breast cancers, and is also associated with other important health outcomes such as mental health, injuries and falls.[7,8]

In our country in general and in our town at particular are also introduce these disaster therefore timely focus and requesting immediate solution. In Debre Markos and Fenoteselam towns the practice, habits, and the perception of people towards the contribution of physical exercise is not that much observed. Therefore the researchers motivated to show potential barriers in the practice of physical activity and physical exercise that lead to non-communicable disease, in the near future exercise scientist showing that, most of the time factors alienated to poor physical activity, poor wearing and passing principles sport like bad eating habit, addiction, lack of resource (infrastructure) like coaches, material and facilities are among expected variables. [5]

\subsection{STATEMENT OF THE PROBLEM}

As we know, now a day the community health is improved not only by taking different medicines but also by involving in physical exercise, however still many people have challenged by non- communicable disease. The problem was directly associated with the perception and attitude of people prescription (lack of time, social influence, lack of energy associated to interest, fear of injury, lack of skill, weather condition and environment, age, heredity, lifestyle (exposure to exercise, nutrition, hygiene), and lack of resource are still fertile ground for 
chronic respiratory disease (such as chronic obstructed pulmonary disease, asthma), blood pressure (hypertension), cancer, cardiovascular (like heart attack, stroke), diabetes and obesity are serious problems.

To say this, the researchers had seen the Debre Markos and Fenoteselam town community being correlated and evaluated with physical exercise is not that much observed, therefore as the researcher tried to be dig out in our study what were the major barriers in the engagement of physical fitness? Does it poor physical activity or habit behalf of community? Does it hinder the practice of experts with sport ethics problem? Does it awareness problem besides of the benefits of sport practice? Does it related to resource like human, material and facilities (sport infrastructure)? On the contrary the symptom of NCD had been watched since the data obtained from health centers (Debre Markos referral hospital and Fenotselam hospital). When we had seen the importance of physical exercise soon or later different study assures; physical activity is more preferable than taking medication in order to improve the society health condition. To this end the Researchers answer the following Research questions.

\subsection{RESEARCH QUESTIONS}

In order to conduct this research, we the researchers were tried to investigate the following basic research questions.

1. Are there Gym and fitness centers available in Debre Markos and Fnotselam towns?

2. To what extent the community is aware about the importance of physical exercise related to health?

3. What are the major factors which affects the participation of the community towards regular physical activities?

4. To what extent the community involving in physical exercise in the available sport arena and fitness center?

\subsection{OBJECTIVES OF THE STUDY}

\subsubsection{GENERAL OBJECTIVE}

The general objective of this research was to investigate the perception of people to prevent non-communicable diseases" through physical activities

\subsubsection{SPECIFIC OBJECTIVES}

1. To assess the current status of sport arena and fitness centers

2. To assess the communities awareness about the importance of physical exercise to prevent NCD

3. To identify the major barriers of the community towards the effects of involvement of regular physical activities on NCD

4. To assess the perception of community towards the importance of physical exercise in order to prevent NCD

\subsection{SIGNIFICANCE OF THE STUDY}

This study was conducted to identify the major challenges in the practice of physical fitness in Debre Markos and Fnoteselam town community alienated to prevent selected NCD chronic health conditions. Therefore the researchers of this study hopes that the findings of the research would contribute to:

* To indicate the major barriers of the people habits and sport culture, the importance of exercise to society active life style, healthy and health related issues are timely researchable area since low income country people have not obtained sufficient medical services because the diagnosis and treatment costs are very expensive,

* To solve the major problem enhancing the practice of physical exercise is became the preferable means and no choice, to give insight for experts within streams; and also

* To provide scientific findings for policy makers in behalf of prevention program

\subsection{DELIMATION OF THE STUDY}

This study is delimited to Debre Markos and Fenoteselam towns in different respective population groups and offices such as Debre Markos University, Debre Markos town administration offices workers, East gojjam zone office workers, such as East gojjam Zone administration office, East gojjam Zone educational office, Debre Markos city sport office, East gojjam zone sport office, commercial bank and Fenoteselam town (administration office, educational office and sport office) the total sample size 2200 and a minimum of 600 sample respondents were taken by $10 \%$ rule among this 470 for questionnaire and 130 for interview respondents. Again the scope is delimited in terms of NCD were focused on chronic respiratory disease, like; blood pressure, cardiovascular diseases, coronary heart disease, diabetes and obesity have been profound effect in order to conduct our study would be feasible.

\subsection{DEFINITION OF TERMS}

A non-communicable disease (NCD) -is a medical condition or disease which is called non-infections and nontransmissible disease among people. 
A chronic condition or disease- is a human health condition that is persistent or otherwise long-lasting in its effects. The term chronic is usually applied when the course of the disease lasts for more than three months. Common chronic disease include arthritis, asthma, cancer, diabetes and AIDS

Chronic respiratory disease- is a quarterly peer-reviewed medical journal that covers research in the field of respiratory disease including chronic obstructive pulmonary lung disease (COLD), respiratory failure and obstructive sleep apnea or chronic airflow limitation (CAL) and chronic obstructive pulmonary disease- is a lung disease defined by persistently poor air flow as a result of breakdown of lung tissue (known as emphysema) and dysfunction of the small airways.

High blood pressure (hypertension)- sometimes called arterial hypertension, is a chronic medical condition in which the blood pressure in the arteries is elevated.

Cardiovascular disease- refers to any class disease that affects the cardiovascular system, particularly vital heart (cardiac disease, vascular disease or the blood vessels(arteries, capillaries and vein)) of the brain, kidney, and peripheral arterial disease.

Diabetes- is a condition where the body fails to utilize the ingested glucose properly.

Obesity- is a medical condition in which excess body fat has accumulated to the extent that it may have an adverse effect on health, leading to reduced life expectancy and/or increased health problems.

\section{RESEARCH METHODOLOGY}

\subsection{DISCRIPTION OF THE STUDY AREA}

East Gojjam Zone and Fenotselam Towns were found in Amahara Regional state. They are selected as a place where to conduct this research due to its convenience in relation to time, money and work place for the researchers.

\subsection{RESEARCH DESIGN}

All research needs a foundation for its inquiry, and inquiries need to be aware of the implicit world views they bring to their studies. The research design is the road map in any research work which refers to a plan of action that links the philosophical assumption to specific methods. Thus, a descriptive survey method was used because it was the most appropriate for addressing and explored the intended purpose of this study (to assess the perception of people towards physical exercise and associated factors like (lack of time, social factors (sedentary life style and habits of sport practice, culture of sport ethics, lack of interest, fear of injury, lack of skill), associated to resource (fitness scholars, facilities and equipment's (sport infrastructure alienated to urban plan and transportation with work and residence, health and weather condition) and attitude and the effect of physical exercise in prevention of NCD and what looks like in Debre arkos and Fenoteselam towns' community? To this end, timely among many designs of research descriptive survey methods were employed in this research as it can provide sufficient information regarding the subject.

\subsection{SUBJECT OF THE STUDY}

As stated in chapter one the participants of this study would be delimited in Debre Markos and Fenoteselam towns selected sector workers a minimum of $10 \%$ rule the proportion of the total sample size $(\mathrm{N}=2200)$, among this we were taken $(n=600)$ sample respondents which means 470(332 male and 138 female) respondents for questionnaires, and 130(87 male and 43 female) for interview, both in Debre Markos and Fenoteselam town separately N1- Debre Markos $=1200$, N2 Fenoteselam=1000, therefore the proportional formula for the questionnaire and interview is represented by $\mathrm{P}=\mathrm{Ni} \mathrm{X} n / \mathrm{N}, \mathrm{i}=1,2 \mathrm{P} 1=\mathrm{N} 1 \mathrm{Xn} / \mathrm{N}=1200 \mathrm{X} 600 / 2200=327$ and $\mathrm{P} 2=\mathrm{N} 2$ $\mathrm{X} n / \mathrm{N}=1000 \mathrm{X} 600 / 2200=272$. These means first from 600 sample population within this 599 for questionnaire and interview based on place, which means 224 for questionnaire and 103 for interview were taken from Debre Markos town together with Fenoteselam town therefore, 272 for questionnaire and interview within this again 200 for questionnaire and 72 for interview were taken from Fenoteselam town purposively. On the other hand jointly, for questionnaire and interview based on sex, which means 600 (419 male and 181 female) sample population from Debre Markos and Fenoteselam town, we were taken purposively.

\section{Questionnaire}

Firstly from Debre Markos town for questionnaire we were taken 224 respondents based on the division of those sex 192 male and 32 female representatives,

Secondly from Fenoteselam town we were taken 200 respondents for questionnaire based on the division of those sex 178 male and 22 female representatives,

\section{Interview}

Thirdly from Debre Markos town we were taken 103 respondents for interview based on the division of those sex 88 male and 15 female representatives,

Fourthly from Fenoeselam town we were taken 72 respondents for interview based on the division of those sex 60 male and 12 female representatives, 


\subsection{DATA COLLECTION TOOLS}

In this research, the data collection tools employed questionnaires, interview with focus group discussion and document analysis in triangulation manner. The reason why the researcher chooses these methods is to get valuable and reliable data for outshined barriers of physical exercise and causes of prevention disease (NCD) in the case of Debre Markos and Fenoteselam towns.

\subsubsection{QUESTIONNAIRE}

A questionnaire is a data collection tool in which written questions are presented that are to be answered by the respondents in both close ended and open ended question form and likert scale because it is the most commonly used method in inquire therefore the respondents are responding their answer with a pre sheet on the given space accordingly.

\subsubsection{INTERVIEW}

Interviews are a type of survey tools where questions are conducted in face to face or personal contact situation of two parties the interviewee and interviewer. The interview is like a conversion and has the purpose of obtaining information relevant to a particular research theme (Kumar, 1999). The researcher's technique would be employed focus group discussion, semi- structured interview (the purpose of this semi- structured interview is to give the opportunity for the free flow of information between interviewer and interviewee).

\subsection{SOURCES OF DATA}

Documents are obtained from valuable primary and secondary sources of information such as questioner, interview and texts, newspaper, minutes of meetings, articles, letters, diaries, memos or scripts, etc. these were manual or electronics obtained from clients and health centers.

\subsection{METHOD OF DATA ANALYSIS}

In this study, both qualitative and quantitative mixed analytical research methodology procedure would be employed, for reference to this, Flick (2002) as quieted Muluken (2006) suggested that qualitative and quantitative methods should be viewed as corresponding rather than contestant camps. The researchers offered the questionnaires checked by statisticians as pilot test first for data validity and reliability and the questionnaires would be distributed accordance with other tools such as prepared interview, observation and gathering relevant documents from target groups for proper handling of data. The techniques of data collected procedures employed by stratum and purposively utilized based on availability accordance with random sampling and then the responses tabulated and analyzed through percentile score.

\section{3 .ANALYSIS OF DATA AND INTERPRETATION}

The following table here after shows the questionnaire and interview question had been necessary designed to handle with simple percentile score all items and alternatives, would be treated entirely based on the study objectives and our basic research questions. Therefore the respondents respond by Amharic as much as possible, it is managed and translated in to English genuinely and accordingly, the major hindering barriers. To saying this here after the researchers employed certain symbols represents Distributed Questionnaire (DQ), Return Questionnaire Response (RQR), Demographic Information (DI), and Questionnaire (Q), Interview (I), Propose for Interview (PI), Interview Results (IR).

Table1. Demographic information

\begin{tabular}{llll}
\hline Characteristics & & frequency & Percent \\
\hline Sex & Male & 332 & 70.63 \\
& Female & 138 & 29.36 \\
& & & \\
& $15-20$ & 10 & 2.12 \\
& $21-25$ & 92 & 19.57 \\
& $26-30$ & 218 & 46.38 \\
Education level & $31-35$ & 26 & 5.53 \\
& 36 and above & 124 & 26.38 \\
& & & \\
& Below twelve & 10 & 2.12 \\
& Certificate & 10 & 2.12 \\
& Diploma & 217 & 46.17 \\
& Degree & 211 & 44.89 \\
& MSc \& above & 22 & 4.68 \\
\hline
\end{tabular}

As shown in table 1, in the demographic information (DI) or at the participant respondent's sex were lay down 332(70.63\%) male's and138 (29.36\%) females respectively. The participant respondents age was 
$218(46.38 \%)$ and $92(19.57 \%)$ were significantly place between the ages of 26-30 and 21-25 respectively. In related to education level, $217(46.17 \%)$ and $211(44.89 \%)$ respondent participants were significantly placed between diplomas to degree level respectively.

Table 2 Analysis of initial attitudinal barriers question difficulty among 470 respondents Average score or $\%$ correct response Measure Difficultya

1. Physical activity importance $8.65 \pm 1.6$ (out of 10 ) -1.56 S.E. $=0.08$ Easy

\begin{tabular}{|c|c|c|c|c|}
\hline Question & & & Frequency & Percent \\
\hline \multicolumn{5}{|c|}{ 1. life style } \\
\hline & & Active & 255 & 54.25 \\
\hline & & Inactive & 215 & 45.74 \\
\hline \multirow[t]{5}{*}{2.} & $\begin{array}{l}\text { participation in regular physical } \\
\text { exercises }\end{array}$ & & & \\
\hline & & High (daily) & 37 & 7.87 \\
\hline & & Medium (3 to5 days) & 64 & 13.61 \\
\hline & & Low (below 3days) & 51 & 10.85 \\
\hline & & Very low (sedentary) & 318 & 67.65 \\
\hline \multirow[t]{4}{*}{3.} & $\begin{array}{l}\text { regarding to the benefits of } \\
\text { exercise }\end{array}$ & & & \\
\hline & & Yes & 330 & 70.21 \\
\hline & & No & 79 & 16.80 \\
\hline & & I have no idea & 61 & 12.97 \\
\hline & $\begin{array}{l}\text { regular physical activities } \\
\text { participation \& feelings }\end{array}$ & & & \\
\hline & & Depressed and anxious & 60 & 12.76 \\
\hline & & Feel free and confidential & 290 & 61.70 \\
\hline & & No behavioral changes at all & 120 & 25.53 \\
\hline \multicolumn{5}{|c|}{ 5. goal seating to do exercise } \\
\hline & & Psychosocial & 40 & 8.51 \\
\hline & & Physical fitness & 188 & 40 \\
\hline & & Health oriented & 210 & 44.68 \\
\hline & & If any, Specify & 32 & 6.80 \\
\hline
\end{tabular}

\begin{tabular}{l}
\hline Question \\
\hline 6. $\begin{array}{l}\text { physical inactivity \& level of } \\
\text { confidence }\end{array}$
\end{tabular}

7. reasons for lack of confidence

$\begin{array}{lll}\text { Yes } & 149 & 31.70 \\ \text { No } & 321 & 68.29\end{array}$
8. self-confidence, wellness,
sociability, and politeness

feel I am physically weak

9. Regarding to preventing \& curing

$\begin{array}{lll}\text { Excellent } & 124 & 26.38 \\ \text { Very Good } & 160 & 34.04 \\ \text { Good } & 150 & 31.91 \\ \text { Fair } & 20 & 4.25 \\ \text { Poor } & 10 & 2.12 \\ \text { Very poor } & 7 & 1.48 \\ & & \\ \text { Preventing is preferable } & 470 & 100 \\ \text { Curing } & 0 & 0\end{array}$




\begin{tabular}{clll}
\hline Question & & Frequency & Percent \\
\hline 10. Sleep and physical exercise & Very likely & 45 & 9.57 \\
& Likely & 103 & 21.91 \\
& Some-what likely & 112 & 23.82 \\
& Unlikely & 210 & 44.68 \\
11. I can't see really learning a new & & 9.14 \\
sport & Very likely & 15.31 \\
& Likely & 25.74 \\
& Some-what likely & 49.78 \\
12. Injury frustration & Unlikely & 72 & 11.27 \\
& & 121 & 14.68 \\
& Very likely & 234 & 24.46 \\
& Likely & 53 & 49.57 \\
\hline Question & Some-what likely & 69 & Percent \\
\hline 13. physical activity \& pleasure & Unlikely & 115 & 233 \\
& & Frequency & \\
& Very likely = 3 & 45 & 9.57 \\
\hline
\end{tabular}

According to table 2 above, 255(54.25\%) of respondents leads their daily life leads by labor work not active life style and 215(45.74\%) had been lead sedentary mode of life. This implies that, the life of the respondents in the study lack of the habit of regular fitness programs because of different attitudinal barriers as explained in different parts of the report. Regarding the majority 318(67.65\%) of sample respondents replied that personal enabling reasons and other reasons as shown in the interview part of the paper it lacks physical fitness program. Based on respondents', the benefit of exercise could be improved entire health status, self-esteem and mood as well as reducing symptoms of depression and anxiety by $330(70.21 \%)$.

The majority $290(61.70 \%$ ) of the respondents replied that they were feel free and confidential were participated even in an irregular setting. the primary goal of the respondents' to be engaged in physical exercise, $188(40 \%)$ aimed for developing their physical fitness and 210(44.68\%) aimed for improving their health conditions. This implies that active individuals have high quality of health status. Concerning about the confidence of inactive individuals comparing with active individuals $321(68.29 \%)$ of them replied that they have lower selfesteem and self-management abilities. About their strengthen, 155 (32.97\%) respondents said that they lack one or more physical qualities like, lower self-esteem and self- management abilities when they were compare themselves with others.

Table 3. The current status of the exercise facilities

\begin{tabular}{|c|c|c|c|}
\hline Question & & Frequency & Percent \\
\hline \multicolumn{4}{|c|}{ 14. availability of exercising facilities } \\
\hline & Yes & 50 & $10.63 \%$ \\
\hline & No & 420 & $89.36 \%$ \\
\hline \multicolumn{4}{|c|}{$\begin{array}{l}\text { 15. If your answer is Yes for question No 14, what you } \\
\text { would be your need for regular physical exercises? }\end{array}$} \\
\hline & Very likely & 211 & 44.89 \\
\hline & Likely & 98 & 85.20 \\
\hline & Somewhat likely & 52 & 11.06 \\
\hline & Unlikely & 109 & 23.19 \\
\hline
\end{tabular}

Based on the table 3,420(89.36\%) of respondents said that, there is no exercising facilities at school or at work place, $50(10.63 \%)$ of respondents said that, there is exercising facilities at school or at work place, and 211(44.89\%) of Debre Markos and Fenoteselam towns' respondents said that very likely because of facilities for physical exercise at school or at workplace highly scarce, $98(85.20 \%)$ of the respondents responded that likely, $52(11.06 \%)$ of the respondents responded that somewhat likely and $109(23.19 \%)$ of the respondents responded that unlikely. This implies most of the respondents respond that the shortage of facilities for physical exercise at school or at work place in Debre Markos and Fenoteselam towns are the major bottleneck factors. 
Table 4: lack of interest

16. I want to get more exercise, but I just can't seem to make myself stick to anything.

Frequency Percent

$\begin{array}{lll}\text { Very likely } & 55 & 11.70 \\ \text { Likely } & 96 & 20.42 \\ \text { Somewhat likely } & 147 & 31.27 \\ \text { Unlikely } & 172 & 36.59\end{array}$

According to table $4.55(11.70 \%)$ of respondents respond that were said, very likely because they want to be get physical exercise but not practically work physical exercise, $96(20.42 \%)$ of the respondents respond that were likely, $147(31.27 \%)$ of the respondents respond that were somewhat likely, and $172(36.59 \%)$ of the respondents responding that were unlikely. This implies there is no lack of interest in Debre Markos and Fenoteselam town the respondents respond that unlikely because they wish to make physical exercise.

Table 5: Lack of skill

Question $\quad$ Frequency Percent

17. I don't get enough exercise because I have never learned the skills for any sport

$\begin{array}{lll}\text { Very likely } & 14 & 2.97 \\ \text { Likely } & 111 & 23.61 \\ \text { Somewhat likely } & 112 & 23.82 \\ \text { Unlikely } & 233 & 49.57\end{array}$

According to table 5 above, 14(2.97\%) of the respondents respond that very likely because there is a lack of any skills of physical exercise, $111(23.61 \%)$ of the respondents respond that likely, $112(23.82 \%)$ of the respondents respond that somewhat likely, and 233(49.57\%) of the respondents respond that unlikely. This implies that in Debre Markos and Fenoteselam town most of the significant respondents responding unlikely response, because of they need to have learned new skills of any sport.

Table 6: Barriers associated with health condition

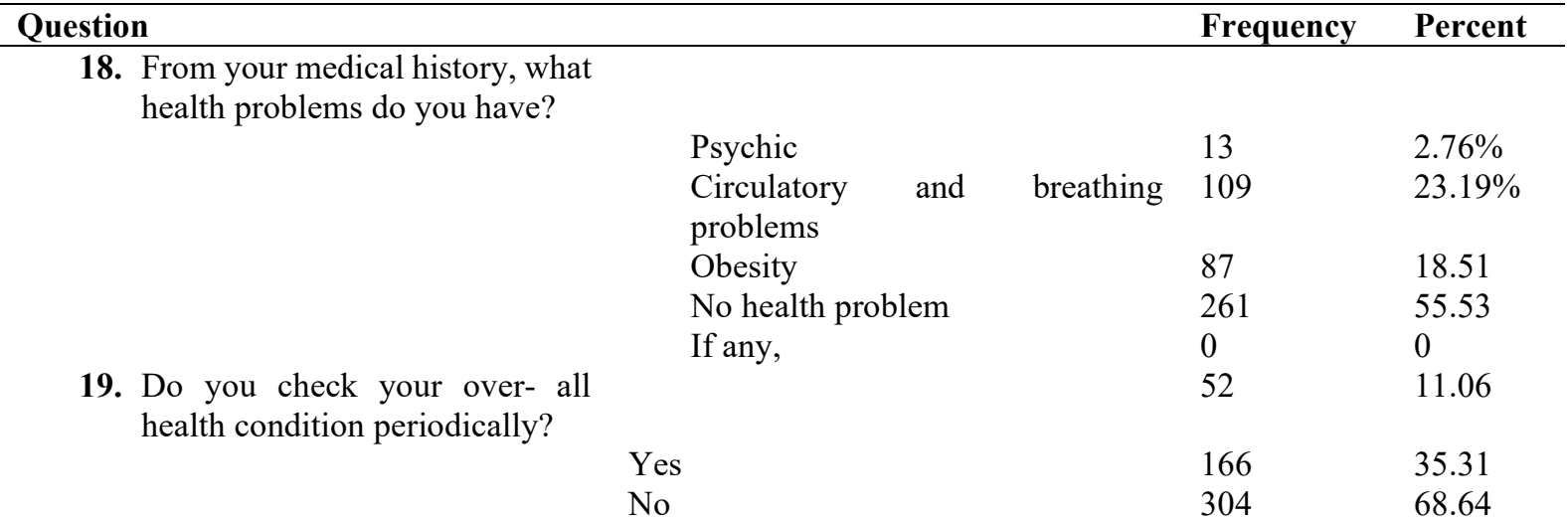

From the above table $6,13(2.76 \%)$ of the respondents responded that were facing psychic health problem, $109(23.19 \%)$ of the respondents responded that were having circulatory and breathing or respiratory health problem, $87(18.51 \%$ ) of the respondents responded that were having obesity, 261(55.53\%) of the respondents responded that were free from any health problem. This implies that, more than half of the respondents responding the communities are healthier, $166(35.31 \%)$ of the respondents responded that were yes response because the community having the habits of periodical checkup about entire health condition and 304(68.64\%) of the significant respondents responded that were said "No" response that means the significant number of people haven't the trends of periodical checkup about the entire health condition. This implies that most of the communities have not enough experience about periodical checkup about entire health status.

\section{SUMMARY,FINDINGS, CONCULUSION AND RECOMMENDATION}

\subsection{SUMMARY}

The major purpose of this study was attempted to the perception of people towards physical exercise and its challenges and opportunities in the process of preventing selected NCDs through physical exercise.

To this end the study tries to answer the following basic research questions:

1. Are there Gym and fitness centers available in Debre Markos and Fnotselam towns?

2. To what extent the community is aware about the importance of physical exercise related to health?

3. What are the major factors which affects the participation of the community towards regular physical activities? 
4. To what extent the community involving in physical exercise in the available sport arena and fitness center?

To conduct this study the researchers delimited to Debre Markos and Fenoteselam towns in different respective population groups and offices society. And the total sample size 2200 and a minimum of 600 sample respondents were taken by $10 \%$ rule among this 470 for questionnaire and 130 for interview respondents. Each office has been selected by stratified sampling based on purposively expected availability of information and participants were be categorized according to their demographic placement such as sex, age, education and habit of involvement then followed by simple random sampling techniques. In this research, the data collection tools employed questionnaires, interview with focus group discussion and documents would be analyzed in triangulation manner. The reason why the researchers chooses these methods is to get valuable and reliable data for outshined barriers of physical exercise and causes of prevention disease (NCD) in the case of Debre Markos and Fenoteselam town. After that the questionnaires were administered and the data was collected, tailed, analyzed and logical conclusion and recommendation was reported.

\subsection{FINDINGS}

Based on the data analysis the following major findings were obtained:

* Lack of awareness about the benefit of physical exercise, poor practice of life style associated to income and routine manual work, cold weather condition, shortages of the expert's, lack of commitment and schedule in order to join in physical exercise at the regular base are among the raised constraints.

* The scarcity of facility there is a shortage of facilities and equipment's to invite physical exercise as community level even though having very little access in the sport infrastructure, the community does not uses these infrastructures properly.

* The scarcity of equipment there is a shortage of budget and equipment's are the major reasons as constraints.

* Lack of skill and attitude there is less participation in the available sport arena and regular physical fitness programs so weak, the reasons are life styles; lack of personal enabling, confidence of inactive individuals comparing with active individuals replied that they have lower self-esteem and selfmanagement abilities for engaging in physical exercise.

* Lack of interest this implies there is no lack of interest respondents respond they wish to make physical exercise.

* Time barriers the significant respondents were answered time is not the major hindering barrier in order to engaged in physical exercise

* Social factor majority of the respondents respond, social factor is not the major barrier in order to engage in physical exercise.

* Fear of injury the significant respondents were answered it is not the major barrier in order to involve in physical exercise.

* Health factors the findings implies more than half of the respondents responding healthier however the communities have not enough experience about periodical checkup about entire health status

\subsection{CONCULUSION}

On the basis of the findings the researchers were concluded as follows based on the data obtained from the respondents:

$>\quad$ The majority of the respondent replied less concerning about their participation in regular physical fitness programs because the lifestyle of the respondents lacks the habit of regular fitness programs, personal enabling reasons like the confidence of inactive individuals comparing with active individuals replied that they have lower self-esteem, low participation in their engagement induce different fears, lack of sleep, lack of skill and fear of injury were attitudinal stated barriers

$>\quad$ The respondents were said that," physical exercise is not harmful "so that fear of injury was not the major barrier in order to involve in physical exercise. Regarding to this, most of the significant respondent's responding unlikely response, because of they didn't learn new skills of any sport even though, they wish to make physical exercise.

$>\quad$ The respondents respond that the shortage of facilities and equipment's for physical exercise at school or at work place was the major bottleneck factors regarding to engaged in regular physical exercise program.

$>\quad$ The respondents were said that, "lack of enough time is not the major hindering barrier because the social activities like family, friends and other social issues highly attached with daily activities rather than to engaged in physical activity.

$>$ Respondents replied that the communities have no experience for periodical checkup about entire health status so the cost of preventing is very less when comparing with the cost of curing and they justified that preventing is less complicated and cost minimized. 
$>\quad$ Lack of interest this implies there isno interest in Debre Mmarkos and Fenoteselam town the respondents respond that unlikely because they wish to make physical exercise.

$>$ Time barriers the researchers conclude that the significant respondents were answered that time is not the major hindering barrier in order to engaged in physical exercise

$>$ As social factor concluded as, it is not the major barrier in order to engage in physical exercise.

$>$ Fear of injury concludes that, fear of injury was not the major barrier in order to involve in physical exercise.

$>$ Health associated factors more than half of the respondents responding in Debre Markos and Fenoteselam town the health status implies there is no communities health problem however the communities have not enough experience about periodical checkup about entire health status

\subsection{RECOMMENDATION}

On the basis of the findings and conclusions the following recommendations are drown for proper implementation of effective change of community attitude on the bases of NCDS related to physical activities:

* The government prepared continues awareness creation stage within the community like:

$\checkmark$ Physical activity on rode

$\checkmark \quad$ Preparer the physical activity day per week

$\checkmark$ Crating the awareness for community about the benefit of physical activity by different media.

* The government and the concerned body must be work together to inducing about:

$>$ Advise the community for brisk walking

$>$ Allocate proper annual budget for all physical activity

$>$ Establishing sound policy

$>$ Create access and availability for different stakeholders like governmental service delivery organization, nongovernmental organization and private sectors to plan and work together for sport facilities and equipment's

* The Ministry of education revised physical education and sport science curriculum by incorporating physical exercise program related to NCDs in different educational institutions.

\# The fitness coaches and Nutritional coaches should be work together to minimize NCDs

\section{REFERENCES}

1. World Health Organization. Global Status Report on Non-communicable Diseases, 2014. Geneva: WHO, 2015.

2. Murray CJ, Vos T, Lozano R, Maghavi M, Flaxman AD, Michaud C, et al. Disability- adjusted life years (DALYs) for 291 diseases and injuries in 21 regions, 1990- 2010: a systematic analysis for the Global Burden of Disease Study 2010. Lancet 2012; 380:2197- 223.

3. World Health Organization, 2009.Global health risks: mortality and burden of disease attributable to selected major risks. Geneva,

4. Bloom DE, Cafiero ET, Jané- Llopis E, Abrahams- Gessel S, Bloom LR, Fathima S, et al. The Global Economic Burden of Noncommunicable Diseases. Geneva: World Economic Forum, 2011.

5. WHO (2004). Global Strategy on Diet, Physical Activity and Health: Geneva World Health Organization

6. Joy E (L), et al. Physical activity counseling in sports medicine: a call to action Br J Sports Med 2013;47:4953. doi:10.1136/bjsports-2012-091620

7. Lisa Miles, Nutrition Scientist, British Nutrition Foundation, High Holborn House, 52-54 High Holborn, London WC1V 6RQ, UK. 2007 British Nutrition Foundation Nutrition Bulletin, 32, 314-363

8. WHO (2013). Global Action Plan for the Prevention and Control of Non-communicable Diseases 2013-2020, Geneva; Switzerland:

9. Booth ML, Owen N, Bauman A, Gore CJ. Physical activity preferences, preferred sources of assistance and perceived barriers to increased activity among physically inactive Australians. Pre Med. 1997; 26:131-137.

10. Calfas KJ, Long BJ, Sallis JF, Wooten WJ, Pratt M, Patrick K. A controlled trial of physician counseling to promote the adoption of physical activity. Prev Med. 1996; 25:255- 233.

11. Marcus BH, Bock BC, Pinto BM, Forsyth LH, Roberts LH, Traficante RM. Efficacy of an individualized motivationally tailored physical activity intervention. Ann Beh Med. 1998;20:174-180

12. Morrow JR., Jackson AW, Bazzarre TL, Milan D, Blair SN. A one- year follow-up to physical activity and health. A report of the Surgeon General. Am J Prev Med. 1999; 17:24-3

\section{ACKNOWLEDGMENT}

First we the researchers acknowledge Debre markos University because encouraging and supporting through motivation and finance, second we want to acknowledge responding participants, thirdly as a principal researcher I want to be acknowledge all our staffs and co researchers especially Mr. Awoke Tibebu from the beginning of the issue supporting to their continuous commitment with the whole research organ accomplishment. 


\section{APPENDIX I \\ DEBRE BIREHAN UNIVERSITY \\ COLLEGE OFNATURALAND COMPUTATIONAL SCIENCES DEPARTMENT OF SPORT SCIENCE}

\section{Questionnaire}

\section{Introduction}

Dear respondents! The main purpose of this questionnaire is to collect relevant information about "Assessing towards the perception of physical activities of people in prevention of non-communicable diseases" in the case of Debre Birhan and shewa Robit towns" and to suggest possible recommendations based on the findings. So your sincere cooperation and honesty answering in each question is highly important. Individual data will be kept confidential. Thank you in advance for your cooperation.

Demographic and generalinformation
1.1. Sex Male Female
1.2. Age in years
1.3. Level of education

Direction: please select the appropriate answer and circle or write your responses where necessary.

1. Mode of living
A. Active B. Sometimes activeC. Inactive (Sedentary)

2. How would you describe your participation in regular physical exercises?
A. High (daily)
B. Medium (3to5 days)
C. Low (below 3days)
D. Very low (sedentary)

3. How would you describe sport related services in the town?
A. Very good
B. Good
C. Poor D. Very Poor

4. Do you believe exercise can be quite effective in improving health, self-esteem and mood as well as reducing symptoms of depression and anxiety?
A. Yes
B. No

5. If you fail to participate in regular physical exercise, please rank your reasons from the severe to moderate by putting a number in front of the options.
A. The type and level of severity of impairment
B. Lack of awareness about the benefits of regular physical exercise for health problems
C. Attitudinal barriers of the society
D. Shortage of time
E. Lack of facilities
F. Lack of personal and organizational support
G. If others, please specify

6. If you have been participated in regular physical activities, what were your feelings?
A. Depressed and anxious B. Feel free and confidential C. No behavioral changes at all

7. From your medical history, what health problems do you have?
A. Psychic
B. Circulatory and breathing problems
C. Obesity
D. No health problem
E. If any, specify

8. What will be your primary goal if you want to do exercise?
A. Psychosocial
B. Physical fitness
C. Health oriented
D. If any, Specify

9. If you are inactive, do you believe you are equal or in the range of confidence in your life with other active individuals?
A. Yes
B. No

10. If your answer for the above question is' No', what will be your reason(s)?
A. I feel I am physically weak
B. I lack one or more physical qualities
C. I fall to fulfill self-care skills
D. If any, Specify

11. How do you rate your behaviors in terms of self-confidence, wellness, sociability, and politeness?
A. Excellent
B. Very good
C. Good
D. Fair
E. Poor
F. Very poor 
12. Do you check your over- all health condition periodically?
A. Yes
B. No

13. What do you think about the preventive strategies of non- communicable diseases at community level?

14. Do you think the cost of preventing is greater than curing? Why?

$\longrightarrow$

